\title{
Small decentralised thermal power stations for Refuse-Derived Fuel (RDF)
}

\author{
C. Bülow \\ BREWA Umweltservice GmbH, Germany
}

\begin{abstract}
We discuss a solution to bringing down energy costs and to making a contribution to climate protection.

Small decentralised thermal power stations for RDF with a thermal capacity of $35 \mathrm{MW}$ have some advantages in comparison to large plants. The required amount of RDF (approx. 70,000 t/a) is mostly locally available, which reduces the transport costs considerably. The produced electrical energy (up to $8 \mathrm{MW}$ ) and the waste heat from the thermal power station can be used in an industrial plant.

An industrial plant and a refuse company founded a joint venture and built a thermal power station for RDF in Bremen. They replaced the old coal fired power station with a RDF-plant. Increasing energy costs are replaced by revenue for RDF. The industrial plant is now using the "cheap" energy from the RDF. The refuse company has a reliable customer and stable prices for its waste for long years: a typical win-win situation. After a 3-year operating time the experiences of the RDF thermal power station are positive without exception. The specified emissions are far below the limits.

Furthermore, due to the fact that RDF contains a high proportion of biomass (approx. 45\%) by changing the fuel from coal to RDF, a contribution to climate protection can be made. If the same amount of biogene content would be land filled, a large amount of methane, which is one of the more dangerous greenhouse gases, would be produced.

The RDF thermal power station is built up modularly. The individual components are standardized so that the plant can be built fast and costeffectively. The specific investment costs per ton of RDF are comparable to large plants (>100 MW). Due to the handling of RDF in a closed hall, there is no smell outside the plant. The RDF is burnt at over $870^{\circ}$ degrees Celsius to eliminate all pollutants completely. The steam is led through a back-pressure turbine and then used in the industrial plant.

The modern flue gas treatment plant shows the expected consumption of additives. Since the initiation, the emission limits are constantly considerably below the requested limits of the EU-DIRECTIVE 2000/76/EC.
\end{abstract}




\section{Alternative energy supply through RDF heat power plants}

When municipal solid waste is deposited in landfills, methane is generated due to the anaerobic decomposition of the biogene content of waste. Methane is a strong greenhouse gas and about 21 times more powerful at warming the atmosphere than carbon dioxide $\left(\mathrm{CO}_{2}\right)$. According to the EU landfill directive $(99 / 31 / E C)$ all member states have to reduce their proportion of the waste for land filling considerably in the following years. They have to sort the waste before land filling and to separate out energy-rich fractions for energetic utilization. Currently most of the waste is still being land filled in the EU.

A lot of the EU-member states initially invest in mechanical biological treatment plants. A utilization of the separated middle- and high caloric fractions often does not exist. Due to the high investment costs it is often not possible to finance an energetic utilization. But due to the highly increased energy costs the usage of these fractions as fuel is getting more and more interesting. This especially applies to industrial companies with a high year-round consumption of steam, in particular from the paper-, food- or chemical industry.

This method of cheap and efficient power supply through decentralised small RDF-power stations is increasingly used in Germany. Small decentralised thermal power stations for RDF with a thermal capacity of approx. $35 \mathrm{MW}$ have some advantages in comparison to large plants. The required amount of RDF (approx. 70,000 t/a) is mostly locally available, which reduces the transport costs considerably. The specific investment costs per ton of RDF are comparable to large plants $(>100 \mathrm{MW})$.

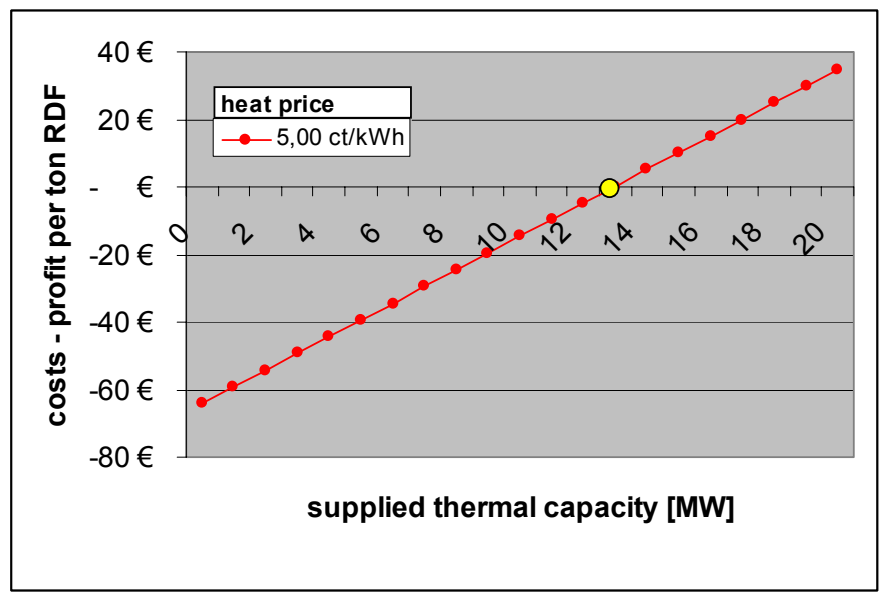

Figure 1: $\quad$ Costs or profit per ton RDF according to the heat supply and price. 


\section{HKW Blumenthal - a positive example for a RDF power station}

An industrial company in Germany, the Bremer Woll-Kämmerei AG (BWK), use the "cheap" energy from the RDF. Until 2004 the BWK had an old coal fired power station to produce electricity and low pressure steam for their production. Increasing repair and fuel costs made it necessary to find a cheaper alternative.

On the other hand there was a waste management company (The AWG) that operates a mechanical-biological waste treatment plant and a land fill. A German law, based on the EU-Directive, made it necessary to sort the waste before dumping and to separate out energy-rich fractions for thermal utilization.

BWK and AWG founded a joint venture and built a thermal power station for about 60.000 tons RDF per year in Bremen in 2005. The old coal fired power station was replaced with a RDF-plant. The industrial plant is now using the "cheap" energy from the RDF. The refuse company has a reliable customer and stable prices for its waste for long years: a typical win-win situation.

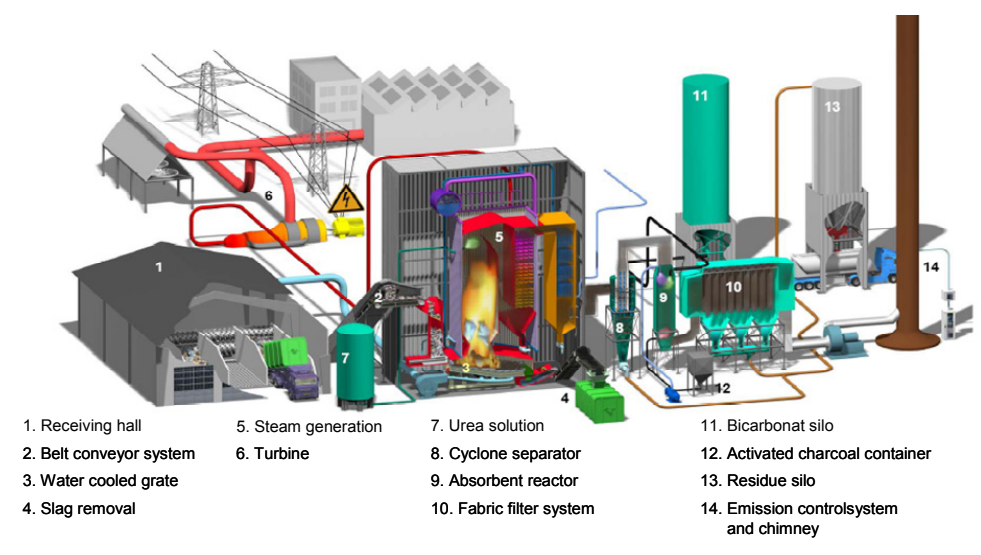

Figure 2: $\quad$ RDF-power plant at the BWK (Germany).

\subsection{Technical description}

The closed transport containers are emptied in boxes. The walking floor conveyor moves the RDF to the back of the box. The RDF is loosened up and dosed to a belt conveyor. Thus different qualities are mixed to a homogenous fuel. The air of the hall is extracted, burned in the vessel and finally cleaned. The conveyor feeds the RDF to the filling hopper of the firing system.

A hydraulic ram feeds the RDF into the combustion zone of the water-cooled grate system. A multiple zone supply of the combustion air ensures complete and proper combustion.

After complete incineration, the slag is the solid residue of the RDF. It is filled into closed containers and disposed of at an accredited dump site.

The heat of combustion is available for steam generation. Water runs through several pipes (the walls of the vessel also consist of pipes), boils and evaporates. 
The steam is separated from the remaining water, superheated and is then ready for use.

The steam actuates a turbine for power generation. The steam is led through a back-pressure turbine and then used in the industrial plant.

\subsection{Flue gas treatment plant}

Urea solution is the initial chemical which supports the flue gas treatment. In a selective non-catalytic process, the nitrogen oxides react to harmless nitrogen (SNCR-process). The cyclone separates coarse dust and its hazardous substances from the flue gas.

For cooling purposes, water is atomised in the absorber reactor. The water evaporates completely. Thus a cooling effect is achieved. The system stays dry. Furthermore, some more chemicals are dosed here for flue gas treatment. Sodium carbonate absorbs acidic components such as sulphur dioxide or hydrogen chloride. Activated charcoal binds possible traces of dioxin, furan, PAH, as well as mercury.

Fabric filter elements separate out the reaction products of the absorber reactor. The reactions of the FGT are finalized in the filtration layer on the fabric filter. The filter system removes the fine dust from the flue gas. The flue gas is totally purified by passing through the filters.

An induced-draft blower exhausts the flue gas from the FGT system and produces a slight under pressure. The flue gas is released to the environment via a chimney of the required height. Automated measuring systems continuously control the clean gas. Violation of limit values sets off an alarm or leads to a plant cut-off.

\section{Experience with the RDF-plant}

After a 3-year operating time the experiences of the RDF thermal power station are positive without exception. The RDF is burnt at over $870^{\circ}$ degrees Celsius to

Table 1: $\quad$ Emissions of the RDF-power station 2007.

\begin{tabular}{|l|c|c|}
\hline & $\begin{array}{c}\text { limit value 17.BImSchV } \\
\text { (average per day) }\end{array}$ & $\begin{array}{c}\text { average per day } \\
\text { 2007 }\end{array}$ \\
\hline nitrogen oxide & $200 \mathrm{mg} / \mathrm{m}^{3}$ & $168 \mathrm{mg} / \mathrm{m}^{3}$ \\
\hline sulfore oxide & $50 \mathrm{mg} / \mathrm{m}^{3}$ & $11.6 \mathrm{mg} / \mathrm{m}^{3}$ \\
\hline dust & $10 \mathrm{mg} / \mathrm{m}^{3}$ & $0.7 \mathrm{mg} / \mathrm{m}^{3}$ \\
\hline carbon oxide & $50 \mathrm{mg} / \mathrm{m}^{3}$ & $20.3 \mathrm{mg} / \mathrm{m}^{4}$ \\
\hline carbon & $10 \mathrm{mg} / \mathrm{m}^{3}$ & $0.6 \mathrm{mg} / \mathrm{m}^{3}$ \\
\hline hydrogen chlorine & $10 \mathrm{mg} / \mathrm{m}^{3}$ & $7.6 \mathrm{mg} / \mathrm{m}^{3}$ \\
\hline heavy metal & $0.5 \mathrm{mg} / \mathrm{m}^{3}$ & $0.001 \mathrm{mg} / \mathrm{m}^{3}$ \\
\hline dioxine & $0.1 \mathrm{ng} \mathrm{Teq} / \mathrm{m}^{3}$ & $0.001 \mathrm{ng} \mathrm{Teq} / \mathrm{m}^{3}$ \\
\hline
\end{tabular}

* German law - dependence on EU-directive 2000/76/EC. 
completely eliminate all pollutants. The modern flue gas treatment plant shows the expected consumption of additives. Since the initiation, the emission limits are constantly considerably below the requested limits of the EU-DIRECTIVE 2000/76/EC.

\section{Advantages for environment}

Due to the fact that RDF contains a high proportion of biomass (approx. 45\%) by changing the fuel from coal to RDF, a contribution to climate protection can be made. If the same amount of biogene content would be land filled, a large amount of methane, which is one of the more dangerous greenhouse gases, would be produced. Furthermore fossil fuel is replaced by fuel with high biogene content. $\mathrm{CO}_{2}$-emission from biomass combustion will account to cero dependence on the rules of the Kyoto protocol.

According to the rules for "clean development projects" and according to the biogene content of the $\mathrm{RDF}$, the new power plant in Bremen can reduce more then 100.000 tons $\mathrm{CO}_{2}$-emissions $\left(\mathrm{CO}_{2}\right.$-equivalents) per year. For equivalent projects in development countries this is an additional possibility to finance "waste to energy"-projects. 